\title{
DEVELOPING AN EXPERT COMMUNITY AND DEFINING ITS ROLE IN THE POLITICS AND DECISION-MAKING OF A WORLD HERITAGE CITY: THE EXPERIENCE OF BAMBERG
}

This article investigates the role of expertise and the expert community through local politics and decision-making in a World Heritage City. The expert public community and its inclusion in decision-making are important factors influencing the successful coordination of public interests. The authors demonstrate how developing forms of public governance change the local expert community and transform its structure and core principles, leading to more open and democratic expertise. Using the case study of local urban politics, the authors illustrate that the social authority of expert knowledge and its influence on decision-making is increasingly dependent on public opinion and the diversification of the structures of expert communities. The latter implies, in particular, the inclusion of citizens who do not have formal expert status but who have sufficient experience and authority to influence urban policy. Using the example of the World Heritage City, the authors consider cases where the harmonization of the interests of the participants of urban policies requires an unusual approach from the public administration, taking into account its obligation to follow formal procedures and regulations and its need to ensure greater involvement of citizens in the decision-making process. Our research showed that, in some situations, these recommendations were more authoritative and earned a higher degree of trust from the citizens than recommendations from people with formal expert status. This trend is in line with larger changes in public administration, which is becoming more adaptive, complex, polycentric, and oriented towards productive cooperation. Expert communities are becoming more fragmentary due to the active involvement of actors who, by

Iuliia Eremenko - Postdoctoral Researcher, Trimberg Research Academy Starter Project, University of Bamberg, Germany. E-mail: eremenko.iuliia@gmail.com

Kirill G. Filimonov - Junior Researcher, Institute for Demographic Research-Branch of the Federal Center of Theoretical and Applied Sociology of the Russian Academy of Sciences, Moscow, Russian Federation. Email: kirill.filimonov@polit.msu.ru 
their socio-professional status, are not formal experts but have significant experience and social influence, especially in the local community.

Keywords: expert community, World Cultural Heritage, urban conflicts, shared expertise, local communities

DOI: 10.17323/727-0634-2021-19-2-327-338

Contemporary models of democracy have transformed significantly over the past decades, influenced by factors that contribute to change, such as crises of parliamentary institutions, the influence of new media, and demands for openness and accountability as core principles of public governance systems. Changes again produce some governability issues that need to be solved, such as finding new means of communication between policy actors (Liston et al. 2014), developing civic participation (Hafer, Ran 2016) and civic infrastructures (Zhelnina, Tykanova 2019) for consensus-oriented policies and good governance. The political influence of experts is regarded as one of the most important factors affecting public policy, and communities of experts known as policy advisory systems have become an inseparable part of public governance systems performance (Craft, Howlett 2012). The expert presence in governing institutionalised as public bodies, bringing together academics and policy experts having knowledge of the state of affairs in different areas of society, became an indicator of good governance.

This emerging trend of expert influence in governance and public policy has prompted researchers to conceptualise a form of expert power known as epistocracy. While some researchers even proposed the conceptualisation of a 'new branch of power' designed to solve policy issues effectively (Vibert 2007), others are concerned that 'epistocracy' is a growing threat to democratic politics (Urbinati 2014), when experts dominate public policy and decision-making, providing their recommendations to public authorities who are more focused on expert proposals than the opinion of voters. Nevertheless, policy advisory research demonstrates that the epistocracy narrative is often exaggerated, and here we emphasise that experts themselves facilitate this narrative to promote the idea of epistocracy.

We also notice that this epistocracy trend in public policy and governance research is now clearly observable, and there are many prospective case studies emphasising the local contexts of the political influence held by expert communities. In addition, we believe that research on the local context of epistocracy is one of the best ways to demonstrate how experts and expert communities transform governance and public policy. This approach must be multi-level, implying that our analysis is sensitive to the peculiarities of the social structures we observe, meaning that each of these structures (local, national, or global) requires its own kind of expertise.

In our study on expert performance, drawing on the example of the local context of urban politics, we explore the changing role of expertise employed 
for the purpose of good governance, that in our case is aimed at ensuring a balance between expert solutions referenced by administrations and public pressure from citizens to have more power in local politics. As a result, we find that the previous role of experts as mediators, as the sources of balance and of the coordination of interests, mediating government and society (Joerges, Nowotny 2003), is challenging. We suggest that this capacity of experts to mediate in governance and public policy is for now diminishing, making public governance systems less stable. In addition, for the purpose of more stable and effective governance, the strong influence of experts on the legitimisation of decision-making must be supplemented by strong civic participation, not only in decision-making but also in expert performance. On the basis of local case studies, this article aims to demonstrate how this is possible.

\section{Sources and Methods}

The social sciences respond to the governance challenges described above by seeking new approaches to policy coordination (Peters 2018; Trein et al. 2019; Steinebach et al. 2019), overcoming information asymmetries in public administration (Eckhard 2020) and developing concepts that capture the complex, multi-layered and non-linear nature of public governance (Thiel et al. 2019; Segato, Berthod 2019). In relation to this, one concept'collaborative governance' (Ansell, Gash 2008) - attracts our particular attention. This concept, in our view, captures the dynamics of expert communities and their inclusion in power-governance relations, at least in the local contexts we have observed.

Collaborative governance is an emerging approach focused on polycentric governance, assuming that governance structures (local, state or international structures) interact directly with non-state actors in collective decisionmaking. According to this approach, policy actors focus on public deliberation and consensus building through dialogue. The goal is to develop or implement policy, resolve public administration issues, coordinate public programs, and evaluate their implementation (Ansell, Gash 2008). Such communications, involving as many interested and influential actors as possible, are characterised by face-to-face dialogue and smaller-scale stories and builds a higher level of trust between the actors, promotes mutual recognition and respect for positions, shared responsibility, and a common understanding of the issues at stake (Ibid: 544).

We suggest that this concept has more explanatory capacity precisely on the local level, taking collaborative governance as the general framework of the study. Through this framework, we demonstrate the complexity of public governance systems, balancing between the demands of epistocracy and civic participation. This complexity involves the co-existence at the local level of politics of various sources of expertise, and the advisory system which, taken 
together, is multi-level, more open, fluid, and fragmented. Such a configuration of expert performance makes the public governance system more democratic and deliberative, engaging policy actors, who are not experts by profession but have significant experience and public influence.

Our case study is the local urban politics of the German city of Bamberg concerning the issues of World Heritage. Bamberg is, as we propose, a relevant example of a local community with polycentric, multi-level governance, constantly needing to coordinate the interests of residents, the city administration, businesses, professional groups and international organisations (in this case, UNESCO). Under the influence of all these groups, the expert community is developing, trying to balance interests, searching for governance that is more flexible. We assume that the configuration of expert performance influencing urban governance includes several mutually overlapping groups of expertise: official cultural heritage experts, academic experts, international experts of UNESCO and citizen initiatives, those who have practical experience and knowledge of the situation but without the formal status of experts. An analysis of their activity seemed to us a promising means to explore the balancing between epistocracy and civic demands.

Concerning this case, we propose our concept of 'shared expertise' (analogously with 'shared governance'). This concept describes cases when different forms and levels of expertise overlap within the framework of collaborative governance, with the aim to solve conflicts and policy issues effectively, engaging official experts solution, on the one side, and the participation of an active citizenry with valuable knowledge and experience, on the other.

The empirical part of our study is based on data from semi-structured expert interviews collected between October 2018 and May 2020. We analysed the positions of different actors engaged in urban politics related to the shaping of Bamberg's image as a city of World Heritage. We have identified three groups of experts, acting at the local level of urban politics and participating in public policy and decision-making regarding city development issues. We have paid particular attention to the activity of the citizen initiatives mentioned above; they are 'local experts' on World Heritage issues in Bamberg, and their meaning matters in urban politics because of their significant experience and influence in public affairs. Their activity, along with that of official experts and the academic community, gives us grounds to argue that shared expertise as a governance practice of expertise is restructuring in conditions of balancing between democracy and epistocracy.

\section{Shared expertise and Urban Politics: Experience of Bamberg}

Bamberg was designated a World Heritage Site in 1993. This has shaped its practice of working with experts and citizens for almost 30 years. The city has come a long way in solving the issues associated with World Heritage 
policy: from the decisions based only on expert solutions to what we call 'shared expertise.' In the case of shared expertise, we observe a tendency when the intentions of international bodies such as UNESCO or Bamberg city administration come up against the citizens' preferences for city development. The citizens do not want to follow certain international bodies' orders and allow the city administration to act according to these orders. In addition, under the pressure of public opinion, the city administration is forced to rely not only on international experts and academics but also citizen participation in urban politics and decision-making.

Today, the expert community and expertise are moving from a situation of a closed group that decides what the World Cultural Heritage (WCH) is and determines its fate to a position that some researchers declare as follows: 'We are all experts in the field of heritage' (Schofield 2014:2). Gradually, this position is shared by a growing number of proponents, who argue that people have the right to feel and articulate heritage through the senses, with no one expert having the exclusive right to say how to evaluate objects properly (Tolia-Kelly et al. 2017). It has been argued that the analysis provided by WCH experts is 'less understood by the public' (Schofield 2015: 423) and that better ways must be found to listen to 'ordinary' but experienced citizens in heritage management, to incorporate their views into policymaking (Schofield 2015: 423; Schofield 2014: 1).

We identified two cases related to finding solutions for changing urban spaces: (1) the case of restoration and (2) the case of construction in the WCH area. We also identified three groups of experts who perform at the local level of urban politics, taking part in harmonising interests in changing the face of the city. The first group are citizens who have the official status of experts and are members of organisations for the protection of cultural heritage: Bayerischen Landesverein für Heimatpflege e.V. (Bavarian Regional Union for the Care of the Hometown, Bamberg) or Stadtheimatpflege Bamberg (Care of the Hometown, Bamberg). The former is funded by the Bavarian State Parliament, while the latter receives a little support from the Bamberg city government. This group most often acts as a third-party mediator in conflicts between private owners of city real estate and the city administration. The second group is from the academic community, the faculty of the local research centres specialising in reconstruction and restoration activities in the $\mathrm{WCH}$ area. Despite the independence of the academics from the city administration, the expert activities that this group conducts cannot be considered completely independent since it is often conducted jointly with the city administration. The third group comprises citizen initiatives, 'local experts' who have acquired expert status through membership in public organisations independent of the city administration: for example, the Schutzgemeinschaft Alt-Bamberg (Association for the Protection of Old Bamberg) and the Interessengemeinschaft interesSAND (Interest group 'interesSAND'). It should be noted that the experience 
of representatives of these groups is often more valuable for solving the problems of cultural heritage preservation and, as noted earlier, is more in line with the interests of the local community.

A large number of the Association for the Protection of Old Bamberg members are retired or specialised experts in history and architecture, who are not part of the city administration and are not in business. The members of this association see their goal as active participation in public discussions and analysis of publicly presented data on construction works by the city administration, as well as finding the best strategy for such works by providing the administration with information on existing archival materials on the structure of a particular building. Representatives of all the groups mentioned above are involved in decision-making on changes to the city's appearance: activists, members of public urban conservation organisations, and cultural heritage protection organisations. All of them constitute members of the expert community and usually act as a third party between private owners and the city administration, often acting as mediators in resolving conflicts. Nevertheless, it should be noted that the involvement of the international expert communities of UNESCO or representatives of the academy is much rarer here. Let us illustrate the structures of this relationship in the example of two cases.

\section{The case of preserving the historic Sound-n-Arts building}

The first case is the situation of the Sound-n-Arts Club building, which is located in the $\mathrm{WCH}$ area on one of the busiest pedestrian streets where the city's breweries, cafes and restaurants are located (Obere Sandstraße 20). As the city prepared for the largest urban festival (Sandkerwa) and safety standards were inspected in August 2019, it was noticed that the façade of the Sound-n-Arts building showed structural instability. The city government issued a ban on the use of the building because of the emergency and threat of collapse. The owners of the club were not the owners of the building but had rented the premises from an investment company that agreed to a reconstruction plan with the city administration after the purchase but had never implemented it, having received the tax deductions due to such expenditures on restoration. After the announcement of the possibility of the building collapsing, the city administration tried to get in touch with the building owners but was unable to do so. Then the decision was made to call the emergency services. They built special structures that took some of the load off the facade and supported it. Specialists revealed that the reason for the emergency condition of the building was the removal of the supporting structures to increase the space inside the building.

The situation provoked a multi-level conflict: a local discussion ensued, which went beyond the city's agenda to the national level (since the investor company was not registered in Germany). Because of its significance, the city 
administration was also obliged to inform the UNESCO coordinators about the problems encountered. The city administration did not attempt to contact the investment company, while experts from the Association for the Protection of Old Bamberg organized an online petition demanding that the owners renovate the building or hand it over to the city. Under public pressure, the investment company came forward after a while but offered to sell the building back from the city at an inflated price. In late 2019, sale documents were signed. The original proposed purchase price was more than halved during negotiations. The alternative to the purchase could have been a lawsuit, which the city administration did not want because of the high legal costs coupled with reputation losses and loss of the city's historical image.

The situation was also complicated by the fact that the actions of the city administration, in this case, were no longer perceived as the best (or good governance) in terms of preserving the WCH due to the fact that the administration could not sufficiently control the process of restoration and the operation of the building and only got involved in resolving this issue at a stage when the building had already begun to collapse. In the eyes of the citizens, the image of the city administration as an authoritative body and a subject making competent decisions was lost.

For this reason, the city administration decided to involve local experts. In resolving the situation, the townspeople participated, a large proportion of whom represented the third of the groups we identified-old-timers with experience and authority. The opinion of these experts was better reflected and, ultimately, had a greater influence on public opinion and decisionmaking. They influenced both sides, the city administration and the representatives of the host company. According to the city administration, the influence of or pressure from this group of experts made the former owner change his mind and sell the building. Local experts could not stay away when a building in the city's historic centre was being destroyed before their eyes. They were ready to ally with the city administration, which had lost some of the citizens' trust.

In this case, we can observe the manifestation of cooperative management, which is revealed by involving citizens in decision-making and restructuring the expert community. In this situation, the position of citizens, whose influence was conditioned by their social authority and knowledge of the situation, rather than the formal status of an 'expert', carried more weight. For the city administration, such an approach allowed it, first, to resolve the issue related to the irresponsible behaviour of a private company, including through pressure from the public represented by expert citizen initiatives; second, the involvement of the latter in the professional discussion of the situation allowed the reduction of social tension among citizens dissatisfied with incompetent management and the initiation of the development of more intelligent solutions for public management. 


\section{Case transformation of the World Heritage Centre building}

The second case study is the project to build a new World Heritage Centre building in the WCH area in Bamberg, which has become one of the most high-profile projects for the city, being erected on the site of an old mill in the vicinity of the Old Town Hall, a major symbol of the city. A source of social tension here was the involvement of big business, which the city community had not encountered before, concerned about the intentions of businesses to build up the city centre and thus disrupt the integrity of its historical image. The project required a lengthy reconciliation of interests and active work with various groups from the city's expert community. The city administration had to consider several requirements: (1) the project should solve the issue of modernizing the remains of the old mill building, which interfered with the formation of the visual appearance of the city; (2) the project should not be costly for the city budget; (3) the project should comply with UNESCO World Heritage preservation requirements; (4) the project should be agreed upon by residents to avoid protest activity; (5) the building should become a new landmark that attracts tourists. In order to take account of all these requirements and make a balanced and qualified decision, the city administration tried to diversify the expert community as much as possible. Involving only international experts to assess the situation and the prospects of the project was insufficient. Decisions based solely on the recommendations of international experts could have caused dissatisfaction among citizens and potential conflict with the prospect of reaching the federal or even European level. For this reason, to provide expert support in coordinating interests, proactive, authoritative citizens professionally studied the architecture of the city. It should be noted that their involvement in the process does not mean that international experts were distrusted. However, the use of different levels, international (represented by UNESCO) and local expertise, contributed to confidence on the part of citizens in the project, in the work of the city administration and in the private investors who were interested in the project and owned the land where the Centre was built.

The Centre's building was eventually built at a private investor's expense and the construction had an undeniable value to business, as a turbine was installed under the building, generating energy for 300 households. The investor also owns a restaurant on the first floor of the constructed Centre, and the city leases all remaining space from him at a price determined before construction. However, the mere fact that the project was implemented not at the expense of the city budget but with investment funds did not reduce the duration of the conciliation procedures or the number of participants, including citizens and local experts who participated in discussions about the project. Invited 'external' international experts played their role in assessing and confirming the feasibility of the project, taking into account the requirements for World Heritage sites. However, mediators between the various positions of the 
citizens and the city administration were assumed by the local experts - a citizen initiative, whose participation in the project was more long-term than that of UNESCO experts or other Bamberg expert groups.

In this situation, we can see that the city administration, in making the decision to build the Centre and justify its construction, is also focused on reducing communication costs and risks. In this regard, the group of experts discussed above was also involved in the expert support of the process; their participation allowed the administration to justify the decisions professionally but also to ensure their legitimacy, since the citizens, in this case, took some responsibility for changing the historic building and the appearance of the city as a whole.

\section{Conclusion}

The development of expert communities in contemporary democracies is a complex and non-linear process. This is best demonstrated by the local context and practices of urban politics in small cities, especially in cases where executives need to strike a balance between the demands of epistocracy and civic participation, and in conditions of polycentric governance, involving not only local but also international policy actors, as in our cases. Public governance systems that are strongly based on expert performance more than on citizen participation in decision-making are under pressure, and executives are searching for ways to make the expertise more public and deliberative.

The way of facilitating the stability of governance is the practice we call 'shared expertise'. The concept of shared expertise is apt to cases when political and governance actors tend to collaborate and use different kinds of expert performance to legitimise decisions. One such practice is the participation of actors, who often have no formal status of experts. Nevertheless, such actors are deeply involved in resolving local issues, having knowledge of the situation, public authority and a high level of trust from the local community members (in our case, Bamberg citizens). Their public authority and trust sometimes influence public affairs more than that of international experts or academics.

Therefore, sharing - expertise and governance in general- is an emerging trend, when public governance system focused on consensus, and conflict resolution incorporates different actors to solve different issues. In such conditions, the levels and forms of expertise also overlap with each other. This trend demonstrates the complex and multi-level governance of local communities, where executives cannot focus on only one source of legitimation but should be effective in the coordination of different kinds of expertise required by different groups of policy actors. The structure of the expert community and performance becomes more fragmented - at the expense of the active involvement of actors who are not experts by their professional status but have 
relevant experience, authority and influence, especially in local communities. The expertise, therefore, becomes deliberative and even democratic.

We presented two cases when the authority of expert knowledge and its influence on decision-making is increasingly dependent on the public. In the example of Bamberg, we have seen the need for the city administration to respond in a creative manner to the needs of professional decision-making and, at the same time, to take into account the demands of the citizens to participate in decision-making. The desire of citizens to participate is based not simply on their interest and desire to influence decision-making. This desire is supported by their authority, experience, and qualified judgment on urban development issues, which can play a more significant role in public governance than recommendations of experts with appropriate formal statuses.

Therefore, searching for stable forms of public governance leads to flexible forms, including the capacities of epistocracy and democratic participation. In the case of Bamberg's shared expertise, we observe growing possibilities of civic engagement when authorities facilitate citizens' initiatives in expert performance, shaping official positions that make it possible to grant the status of expert to a person who does not officially possess it. The number of such cases is not very high, so the citizens who do not possess this official status continue to act as experts using their authority in the local community and their status as members of a public organisation. We argue that the observation of such practices as shared expertise indicates that their description and analysis are promising for further study and for the solution of public governance issues and effective urban politics.

\section{Acknowledgements}

The text of the article was prepared as a part of I. Eremenko's postdoc project at the Graduate Centre Trimberg Research Academy, TRAc Starter Project (University of Bamberg) with the financial support of the 'Step by Step' programme. The conceptual part of this study, including literature review and the concept of 'shared expertise' was prepared as part of the project N 21-011-32145 'The Concept of Epistocracy in Public Policy: Approaches and Contemporary Russian Practice' funded by RFBR and EISR. The empirical program of study was prepared as part of the research of K. G. Filimonov (The 'Monitoring Integration Processes in Eurasian Economic Union' at Institute for Demographic Research FCTAS RAS (IDR FCTAS RAS)) and as part of I. Eremenko research at the University of Bamberg.

\section{References}

Ansell C., Gash A. (2008) Collaborative Governance in Theory and Practice. Journal of Public Administration Research and Theory, 18 (4): 543-571.

Craft J., Howlett M. (2012) Policy Formulation, Governance Shifts and Policy Influence: Location and Content in Policy Advisory Systems. Journal of Public Policy, 32 (2): 79-98. 
Eckhard S. (2020) Bridging the Citizen Gap: Bureaucratic Representation and Knowledge Linkage in (International) Public Administration. Governance, 34:295-314.

Hafer J. A., Ran B. (2016) Developing a Citizen Perspective of Public Participation: Identity Construction as Citizen Motivation to Participate. Administrative Theory and Praxis, 38 (3): 206-222.

Joerges B., Nowotny H. (eds.) (2003) Social Studies of Science and Technology: Looking Back, Ahead. Dordrecht: Kluwer Academic Publishers.

Liston V., Harris C., O'Toole M. (2014) Bridging Normative Democratic Theory and Internet Technologies: A Proposal for Scaling Citizen Policy Deliberations. Policy \& Internet, 5 (4): 462-485.

Peters G. B. (2018) The Challenge of Policy Coordination. Policy Design and Practice, 1 (1): $1-11$.

Schofield J. (2014) Heritage Expertise and the Everyday: Citizens and Authority in the Twenty-First Century. In: J. Schofield (ed.) Who Needs Experts? Counter-Mapping Cultural Heritage. Farnham: Ashgate: 1-11.

Schofield J. (2015)'Thinkers and Feelers': A Psychological Perspective on Heritage and Society. In: E. Waterton, S. Watson (eds.) The Palgrave Handbook of Contemporary Heritage Research. Basingstoke: Palgrave Macmillian:417-425.

Segato O., Berthod F. (2019) Developing Purpose-Oriented Networks: A Process View. Perspectives on Public Management and Governance, 2 (3): 225-234.

Steinebach Y., Adam C., Hurka S., Knill C., Peters G. B. (2019) Introducing Vertical Policy Coordination to Comparative Policy Analysis: The Missing Link between Policy Production and Implementation. Journal of Comparative Policy Analysis: Research and Practice, 21 (5): 499-517.

Thiel A., Blomquist W. A., Garrick D.E. (eds.) (2019) Governing Complexity. Analyzing and Applying Polycentricity. Cambridge: Cambridge University Press.

Tolia-Kelly D.P., Wateron E., Watson S. (2017) Introduction: Heritage, Affect and Emotion. In: D. P. Tolia-Kelly, E. Wateron, S. Watson (eds.) Heritage, Affect and Emotion. Politics, Practices and Infrastructures. London: Routledge: 1-12.

Trein P., Meyer I., Maggetti M. (2019) The Integration and Coordination of Public Policies: A Systematic Comparative Review. Journal of Comparative Policy Analysis: Research and Practice, 21 (4):332-349.

Urbinati N. (2014) Democracy Disfigured: Opinion, Truth, and the People. Cambridge, MA: Harvard University Press.

Vibert F. (2007) The Rise of the Unelected: Democracy and the New Separation of Powers. Cambridge: Cambridge University Press. 
Zhelnina A., Tykanova E. (2019) Formal'nyye i neformal'nyye grazhdanskiye infrastruktury: sovremennyye issledovaniya gorodskogo lokal'nogo aktivizma v Rossii [Formal and Informal Civic Infrastructure: Contemporary Studies of Urban Local Activism in Russia]. Zhurnal sotsiologii i sotsialnoy antropologii [The Journal of Sociology and Social Anthropology], 22 (1): 162-192. 